\title{
NOTAS
}

\section{Consideraciones acerca de una Guía Bibliográfica: Lexicología y lexicografía de M. Alvar Ezquerra}

\author{
Ana Isabel Navarro Carrasco \\ (Universidad de Alicante)
}

La obra que comentamos (Lexicología y lexicografía. Guía bibliográfica, Almar, Salamanca, 1983, 283 págs.) es uno de los trabajos que ha realizado el profesor Manuel Alvar Ezquerra -en su larga trayectoria- sobre cuestiones relativas a la lexicología y lexicografía. Estas líneas nuestras que hoy ven la luz debieron salir en su momento - 1983 - , sin embargo, debido a determinadas circunstancias - no ajenas a este tipo de publicaciones - no aparecieron. Ahora queremos que estén presentes en esta revista, especialmente si pensamos en que, después de todo este tiempo, aquel Manuel Alvar Ezquerra que hablaba de los aciertos y fallos del Diccionario General Ilustrado de la Lengua Española (Barcelona, 1976, $3^{\mathrm{a}}$ ed. corregida y ampliada, $1^{\mathrm{a}}$ reimp. corregida) de Samuel Gili Gaya (vid. págs. 187-197 de libro) se ha convertido en el Manuel Alvar Ezquerra que ha realizado la nueva redacción de esta misma obra, además de otros muchos Diccionarios VOX.

El libro es una guía bibliográfica comentada sobre estudios lexicológicos, lexicográficos y diccionarios. Pero la recopilación no pretende ser una lista exhaustiva de todos y cada uno de los trabajos que sobre estas materias se han realizado ni tampoco un catálogo de los diccionarios existentes en el mercado. Sólo muestra un conjunto de estudios básicos que sirva de orientación al que se 
inicia en estas tareas, y da -al mismo tiempo- una visión general del abanico de posibilidades que ofrecen las diversas tendencias. El trabajo tiene un gran carácter didáctico, ya que, en muchísimas ocasiones - y al hilo de los comentariosel autor señala aquellas parcelas que deberían ser cultivadas en nuestro país siguiendo otras actividades que se realizan más allá de nuestras fronteras. Es decir, se abren posibilidades de investigación, se muestran cuáles son y se orienta al lector para que escoja el camino que desee.

El libro se divide en «Introducción» (págs. 7-11), «Obras y Estudios» (págs. 12-183) y «Diccionarios» (págs. 185-264), además de un índice de nombres propios y otro de materias.

En la «Introducción» se nos explican los pormenores de la obra: un instrumento de trabajo para estudiantes de nivel superior, profesores de bachiller y de Universidad (cfr. pág. 71). Ésa es la intención del propio autor, pero más adelante veremos cómo el libro va más allá de los fines propuestos y la tarea, más que cumplida, es digna de encomio.

Los materiales se ordenan cronológicamente. Se hace un resumen comentado de cada obra, además de una valoración personal de las mismas. Y nos advierte Alvar Ezquerra que las valoraciones son personales, con lo cual es posible que no salgan a gusto de todos (cfr. pág. 10). Es verdad que esto puede suceder, pero también es verdad que cuando las apreciaciones se hacen partiendo del sentido común —ése que muchas veces nos falla - y con una objetividad rigurosa, esas consideraciones dejan de ser personales para convertirse en colectivas. Así son las valoraciones de Manuel Alvar Ezquerra.

El autor sabe que podría haber hecho un repertorio más amplio, y, por ello, remite a otra obra suya, Proyecto de lexicografía española (1976), donde podemos encontrar una amplia bibliografía sobre estas cuestiones; también nos envía a obras referidas a diversas tendencias de investigación (vid. nota 3 a la pág. 8), y a trabajos sobre la formación de palabras (vid. nota 4 a la pág. 8); y no incluye una lista general de los diccionarios de nuestra lengua porque para ello está el catálogo de Diccionarios españoles (1980), así como el de Maurizio Fabbri (1979).

La primera parte - «Obras y Estudios»— consta de veinticinco trabajos entre los que se comentan «El diccionario que deseamos» de Menéndez Pidal (1945), en el que ya estaban expuestas - de alguna manera- Ias ideas de macroestructura y microestructura con las expresiones respectivas de caudal de palabras y exposición de informaciones (cfr. pág. 29); La méthode en lexicologie. Domaine français de Matoré (1953), que desencanta al lector; una antología de textos lexicológicos: la de A. Rey (1970); tres trabajos cumbres: Étude linguistique et sémiotique des dictionnaires français de Rey-Debove (1971), el Manual of Lexicography de Zgusta (1971) y la Introducción a la lexicografia moderna de Casares (1950), obra capital —-todavía hoy— sobre teoría lexicográfica española. 
Estos tres trabajos deben tomarse como base en las investigaciones lexicográficas. El valor del libro de Zgusta sobrepasa los límites del título y se convierte en una obra de gran interés para investigadores de parcelas léxico-semánticas, donde, como muy bien dice Alvar Ezquerra, es totalmente desconocido.

Como buen profesor e investigador, el autor de nuestro libro señala y abre senderos sobre posibles estudios en nuestro dominio - ya lo apuntábamos anteriormente. Sucede con Structures étymologiques du lexique français de Guiraud (1967), punto de partida para trabajos basados en diccionarios existentes o en materiales cartográficos. Comentando Les dictionnaires. Initiation à la lexicographie de Collignon y Glatigny (1978), se nos advierte que los ejercicios que aparecen al final de cada capítulo son de gran ayuda para ampliar el vocabulario de los alumnos, tipo de trabajo que parece ser desconocido en nuestro país. Respecto a la Introduction à la lexicographie: le dictionnaire de Dubois (1971), en la que se exponen ejemplos del modo en que pueden usarse los diccionarios para el mejor conocimiento de la lengua, se nos dice que este trabajo está por hacer en español. En cuanto a La struttura del lexico de M. Alinei (1974), se nos avisa de que es punto de partida para la elaboración de diccionarios modernos mediante el análisis de rasgos semánticos.

La segunda parte contiene comentarios referentes a nueve diccionarios entre los que se encuentran los más importantes de nuestra lengua. En los diccionarios, además de la consideración y valoración de la obra en sí, aparecen unos análisis minuciosos partiendo del cotejo de unos con otros. Se compara las secuencias nu-, don-,fer-, lac-, mac-, nac-del Diccionario General e Ilustrado de la Lengua Española (1976, $3^{\text {a }}$ ed., $1^{\text {a }}$ reimp.) de Samuel Gili Gaya con el de la Academia (1970) y se llega a la conclusión de que el primero cambia en unas parcelas más que en otras. La obra de Samuel Gili Gaya destierra las voces anticuadas para dar paso a las científicas y técnicas, y posee, por lo demás, un carácter marcadamente enciclopédico, sobre todo por introducir muchos grabados y nombres propios.

Dos diccionarios etimológicos: el de García de Diego, en cuya obra siguió trabajando hasta su muerte, y el de Corominas, el mejor diccionario etimológico del español, además del único diccionario histórico completo (cfr. el Diccionario Histórico de la Academia). El profesor Manuel Alvar Ezquerra, siguiendo una muestra elegida, compara la nueva edición de Corominas y Pascual ( $D C E C H)$ con la anterior $(D C E L C)$. El resultado del cotejo supone - tanto en la macroestructura como en la microestructura- la modificación de un tercio de la obra.

En los comentarios al Diccionario Ideológico de Julio Casares son significativos los ejemplos referentes a la parte sinóptica que el propio Alvar Ezquerra añade. La importancia que tiene la parte analógica se pone de manifiesto al comparar las entradas de la letra e del Diccionario Ideológico con el Diccionario de sinónimos de Gili Gaya: en Casares hay un mayor número de voces. De la parte alfabética se cotejan las entradas que comienzan por or-en el DRAE (1970) y en el Ideológico. 
Las suprimidas por Casares, en esa muestra, son aquéllas que la Academia daba como anticuadas, a la vez que Casares introduce otras que faltaban en el DRAE (1970).

Un diccionario de uso: el de María Moliner, donde se incluyen demasiadas explicaciones gramaticales en ciertos artículos. Alvar Ezquerra aboga por un apéndice gramatical, al igual que se hace en los diccionarios bilingües. Además, María Moliner no sigue ningún criterio para la inclusión de nombres científicos de plantas y animales, los introduce un tanto al azar. Pero más que esto se censura y se rechaza el hecho de que los diccionarios de lengua den cabida a la terminología científica. Éste no es su lugar. El Diccionario de uso aúna las distintas formas de una misma familia léxica, aunque esto, debido a la tipografía empleada resulta - más que una ventaja - un inconveniente para el usuario.

El diccionario inverso de Stahl y Scavnicki tiene gran utilidad para los estudios morfológicos (sufijación, composición y derivación) al ahorrar mucho tiempo y trabajo. Índices inversos, añade Alvar Ezquerra, hacen falta también en las Concordancias.

Respecto al DRAE (1970) se explica por qué un diccionario oficial no puede recoger todas las palabras de lenguajes especializados.

Del Diccionario de voces naturales de García de Diego se valora el carácter motivado del signo lingüístico, pero se echa en falta un índice de palabras estudiadas que faciliten el manejo de la obra.

En varias ocasiones, a lo largo de todo el libro, Alvar Ezquerra hace referencia a la importancia que tiene la cartografía lingüística para la elaboración de diccionarios y vocabularios (vid., las páginas 142, 144, 203, 242 y passim). Otro aspecto que merece la pena destacar es la serie de observaciones acerca de la tipografía de los diccionarios. El diccionario es una obra de consulta, didáctica, informativa, el lugar adonde vamos a buscar el significado de las palabras. En este sentido la claridad, no sólo en la exposición sino también en la presentación, adquiere gran importancia. Si en unos la tipografía favorece la consulta, en otros la perjudica.

No queremos concluir sin dejar constancia de la utilidad que tiene una guía bibliográfica como ésta. Muchas veces, por un título evocador, corremos meses, si no años, tras una obra, y cuando la encontramos resulta que no nos sirve para nuestros intereses; o a la inversa, la desdeñamos de entrada. Y es que el título de un trabajo en sí, a veces, no es indicativo de la obra. Al aparecer el libro resumido y comentado nos aseguramos del interés que puede tener y en qué medida nos servirá de ayuda. En definitiva, nos informamos del contenido de la obra. 